at the poles of the spindle (see photograph). Later, they can no longer be identified as they probably become hidden among the normal and rapidly migrating chromosomes. After six hours, when the destructive action is most evident, some of the 'three-group metaphases' have been observed to participate in the pycnotic effect. The three separate groups sometimes undergo chromatic condensation, giving rise to another peculiar image which could be termed 'three-group pycnosis'. While they are not visible twenty-four hours after the injection, there is still no evidence that all the 'three-group metaphases' are destroyed in this manner.

More detailed observations on the action of hydroquinone and related substances on the bone-marrow and other tissues of the mouse, the rat and the rabbit, and on the cellular changes causing this new type of pathological mitosis, will be published shortly elsewhere.

These experiments were started during a short stay at the Chester Beatty Institute, London, and I wish to express my thanks especially to Dr. P. C. Koller.

Laboratory of Anatomical Pathology, R. Parmentuer University of Brussels, and Centre national de recherches sur la Croissance, Brussels.

${ }^{1}$ Parmentier, R., and Dustin, P., Nature, 161, 527 (1948).

${ }^{2}$ Parmentier, R., Rev. Belge Pathol., 22, 1 (1952).

${ }^{3}$ Levan, A., and Hin Tjio, J., Hereditas, 34, 250 (1948); 34, 453 (1948)."

'Parmentier, R., and Dustin, P., Caryologia, 4, 98 (1951).

\section{A New Method in Staining Bacteria on Microscope Slides}

A NEW method of providing dyes for some of the commoner staining procedures has been developed and tested. A small volume of the required dye solution is prepared according to the appropriate formula. The fluid is placed in a large dish, and rounds of No. 4 Whatman filter paper are soaked in it. After a few seconds the paper is removed by means of flat forceps and hung over a glass rod to dry. The dye-paper is then cut into suitable 'chips'-papers $1 \frac{1}{2}$ in. long by $\frac{3}{4}$ in. wide are found to give good results. One round of $11 \mathrm{~cm}$. diameter paper will provide a useful number of dye-papers which can be stapled together in the form of a booklet, with a plain paper cover. The dye-papers do not stain dry fingers and they can be made by unskilled labour in any laboratory.

For use in simple staining, a drop of distilled water is placed on the fixed film and a dye-paper placed on it ; two more drops of water will give enough concentration of dye to stain the bacteria in the operative time. The paper is then washed off and the film dried.

Papers soaked in the following dye solutions are now in use for simple staining: aqueous crystal violet, aqueous and carbolic fuchsin, and aqueous safranin. Aqueous or carbolic methylene blue is used for demonstrating granular diphtheroid bacteria, and for counterstaining after carbol fuchsin in staining spores by the Ziehl-Neelsen method (carbol fuchsin is followed by a sodium sulphite paper). Carbol fuchsin papers are used for staining capsulated cells and flagella.

The advantages of the dye-paper method, with the dyes so far tested, include: (1) elimination of fluid stains in bottles; (2) economy of dye ; (3) economy of storage space; (4) non-spoilage (as by rubber, oxidation, etc.) ; (5) ease of preparation ; (6) negligible cost.

Department of Bacteriology,

$$
\text { P. H. H. Gray }
$$

Macdonald College,

Que., Canada. Nov. 5.

${ }^{1}$ Gray, P. H. H., J. Bact., 12, 273 (1926) ; 45, 301 (1913).

\section{Elimination of Inconclusive Results in the Treponemal Immobilization Test}

WORKING with Nichols's pathogenic strain in the treponemal immobilization test, it is a common experience ${ }^{1}$ that some sera constantly yield inconclusive results and, further, that from time to time a whole series of results must be discarded, because one or another of the controls shows poor survival of the treponemes.

When the test is performed in an atmosphere of 95 per cent nitrogen and 5 per cent carbon dioxide 'contaminated' with about 0.2 per cent oxygen, inconclusive results are relatively often obtained. Even when all oxygen is removed by slow passage of the air through a heated tube of quartz filled with copper chips, there still remain a few sera giving inconclusive results. Consequently, it is necessary to remove all the oxygen; but even then, satisfactory survival of the treponemes is not always obtained.

It was thought that great reducing power in the survival medium might be of importance. Hence, the treponemal immobilization test was performed with a medium containing four times the concentration of sodium thioglycollate ('Difco') prescribed by Nelson.

Preliminary experiments with increased amounts of sodium thioglycollate showed that it was possible to get just as satisfactory results in the test with the above-mentioned oxygen-contaminated atmosphere as with a 'normal' concentration of sodium thioglycollate in an oxygen-free mixture. When the test was performed with four times the normal concentration of sodium thioglycollate in an oxygen-free mixture, it was to be expected that none or only very few sera would give inconclusive results. As a matter of fact, no inconclusive results have been observed since this modification has been employed (150 sera examined).

Hence it is assumed that substances in the testicular extract from rabbits now and then are able to raise the oxidation reduction balance (redox potential) of the medium to such a level that it is incompatible with satisfactory survival of the spirochætes. However, the same might happen in sera giving inconclusive results in experiments in which other sera give satisfactory results. So far no bad influence of the increased amount of sodium thioglycollate has been observed.

Further experiments are in progress, and it is intended to measure $E h, r H$ and $p H$ through the different phases of the treponemal immobilization test. Special electrodes and beakers, manufactured by Radiometer, Copenhagen, have made this possible. Hans Aage NiELSEN

Serodiagnostic Department,

State Serum Institute, Copenhagen. June 13, 1952.

1 Durel, P., Sausse, A., and Borel, L. J. (personal communication). Nelson, R. A., Amer. $J$, Hyg., 48, 120 (1948), Nelson, R. A., Zheutlin, H. E. C., Diesendruck, J. A., and Austin, P. G. M., (personal communtcation). 